Article

\title{
Dimethylcysteine (DiCys)/o-Phthalaldehyde Derivatization for Chiral Metabolite Analyses: Cross-Comparison of Six Chiral Thiols
}

\author{
Ankhbayar Lkhagva ${ }^{1}$ and Hwan-Ching Tai ${ }^{2, *}$ \\ 1 Department of Chemistry, National University of Mongolia, Ulaanbaatar 14200, Mongolia; \\ a_lkhagva@uncg.edu \\ 2 School of Public Health, Xiamen University, Xiamen 361102, China \\ * Correspondence: hctai@xmu.edu.cn; Tel.: +86-178-500-25-032
}

check for updates

Citation: Lkhagva, A.; Tai, H.-C. Dimethylcysteine

(DiCys)/o-Phthalaldehyde

Derivatization for Chiral Metabolite Analyses: Cross-Comparison of Six Chiral Thiols. Molecules 2021, 26, 7416. https://doi.org/10.3390/molecules 26247416

Academic Editor: Paraskevas D. Tzanavaras

Received: 24 September 2021 Accepted: 25 October 2021

Published: 7 December 2021

Publisher's Note: MDPI stays neutral with regard to jurisdictional claims in published maps and institutional affiliations.

Copyright: (C) 2021 by the authors Licensee MDPI, Basel, Switzerland. This article is an open access article distributed under the terms and conditions of the Creative Commons Attribution (CC BY) license (https:/ / creativecommons.org/licenses/by/ $4.0 /)$.

\begin{abstract}
Metabolomics profiling using liquid chromatography-mass spectrometry (LC-MS) has become an important tool in biomedical research. However, resolving enantiomers still represents a significant challenge in the metabolomics study of complex samples. Here, we introduced $N, N$-dimethyl-L-cysteine (dimethylcysteine, DiCys), a chiral thiol, for the $o$-phthalaldehyde (OPA) derivatization of enantiomeric amine metabolites. We took interest in DiCys because of its potential for multiplex isotope-tagged quantification. Here, we characterized the usefulness of DiCys in reversed-phase LC-MS analyses of chiral metabolites, compared against five commonly used chiral thiols: $N$-acetyl-L-cysteine (NAC); $N$-acetyl-D-penicillamine (NAP); isobutyryl-L-cysteine (IBLC); $\mathrm{N}$-(tert-butoxycarbonyl)-L-cysteine methyl ester (NBC); and N-(tert-butylthiocarbamoyl)-L-cysteine ethyl ester (BTCC). DiCys and IBLC showed the best overall performance in terms of chiral separation, fluorescence intensity, and ionization efficiency. For chiral separation of amino acids, DiCys/OPA also outperformed Marfey's reagents: 1-fluoro-2-4-dinitrophenyl-5-L-valine amide (FDVA) and 1fluoro-2-4-dinitrophenyl-5-L-alanine amide (FDAA). As proof of principle, we compared DiCys and IBLC for detecting chiral metabolites in aqueous extracts of rice. By LC-MS analyses, both methods detected twenty proteinogenic L-amino acids and seven D-amino acids (Ala, Arg, Lys, Phe, Ser, Tyr, and Val), but DiCys showed better analyte separation. We conclude that DiCys/OPA is an excellent amine-derivatization method for enantiomeric metabolite detection in LC-MS analyses.
\end{abstract}

Keywords: chiral metabolomics; rice water; d-amino acids; enantiomer separation; dimethyl labeling

\section{Introduction}

In the post-genomics era, metabolomics profiling has become an important tool in biomedical research [1-4]. For highly complex metabolomes, reversed-phase liquid chromatography-tandem MS (RP-LC-MS/MS) analyses is the standard tool for highthroughput discovery [5-9]. One of the fundamental limitations of RP-LC-MS is the lack of stereoselectivity, but many important metabolites are chiral molecules. Recently, chiral metabolomics has become an area of emerging interest [10-15].

Initial interests in chiral metabolomics began with D-amino acids, which are physiologically active substances in mammals [16,17]. In fact, D-serine, D-aspartate, D-alanine, and D-cysteine are found in many tissues and body fluids, and several D-amino acids are important neurotransmitters in the brain [18,19]. Enantiomeric amino acids and their derivatives may be useful biomarkers and novel drug candidates; their detection is important in pharmacological research, clinical analysis, agriculture, and food science [20-22]. Using isotope tagging, advanced MS instrumentation, and new MS data analysis schemes, it is possible to carry out non-targeted chiral metabolomics profiling and discover novel chiral biomarkers beyond just amino acids [23].

A classic reagent for the derivatization of amine metabolites is $o$-phthalaldehyde (OPA), widely utilized in commercial amino acid analyzers [24-27]. The chemical reaction with 
OPA to form fluorescent isoindole derivatives requires a nucleophilic thiol. Coupling OPA to chiral thiols enables chiral separation via diastereomer formation. Chiral thiols tested for OPA derivatization included $N$-acetyl-L-cysteine (NAC) [28]; $N$-acetyl-D-penicillamine (NAP) [29]; isobutyryl-L-cysteine (IBLC) [30]; N-(tert-butoxycarbonyl)-L-cysteine methyl ester (NBC) [31]; N-(tert-butylthiocarbamoyl)-L-cysteine ethyl ester (BTCC) [32]; N-Rmandelyl-L-cysteine (NMC) [33,34]; and 2,3,4,6-tetra- $o$-acetyl-1-thio- $\beta$-D-glucopyranose (TATG) [34].

In advanced chiral metabolomics profiling, labeling with heavy isotopes is very important for quantification. To our knowledge, no study has introduced isotope labels via thiol/OPA derivatization. We are particularly interested in developing $N, N_{-}$ dimethyl-L-cysteine (DiCys) with OPA as a potential strategy for isotope tags in chiral metabolomics. DiCys can be easily synthesized in one step from L-cysteine by reductive amination (dimethyl labeling), using formaldehyde $\left(\mathrm{CH}_{2} \mathrm{O}\right)$ and sodium cyanoborohydride $\left(\mathrm{NaBH}_{3} \mathrm{CN}\right)$. The fact that $\mathrm{CD}_{2} \mathrm{O},{ }^{13} \mathrm{CH}_{2} \mathrm{O},{ }^{13} \mathrm{CD}_{2} \mathrm{O}$ and $\mathrm{NaBD}_{3} \mathrm{CN}$ are commercially available at relatively low costs means that $+2,+4,+6$, and +8 Da tags can be easily generated via dimethyl labeling $[35,36]$. Moreover, ${ }^{13} \mathrm{C}$ - and ${ }^{15} \mathrm{~N}$-cysteines are also commercially available, which means that up to 10 -plex isotope labeling $(+0-+9 \mathrm{Da})$ is feasible (Figure S1, supplementary materials).

Due to the potential of DiCys/OPA as a versatile isotope-labeling method, this study sought to understand its performance in standard RP-LC-MS analyses of chiral metabolites. DiCys was evaluated against five commonly used chiral thiols: NAC, NAP, IBLC, NBC, and BTCC. The reaction mechanism of DiCys/OPA with amines is shown in Figure 1a, and the chemical structures of the other thiols are shown in Figure 1b. They were compared based on their fluorescence intensity, separation performance, stability, and ionization efficiency for amino acid enantiomers. DiCys/OPA was also compared against Marfey's reagents, which are commonly used for resolving chiral amino acids. Finally, we compared DiCys against IBLC in identifying D-amino acids in aqueous extracts of rice. Our data suggest that DiCys/OPA is an excellent derivatization method to resolve chiral amines in RP-LC-MS metabolomics profiling.

a

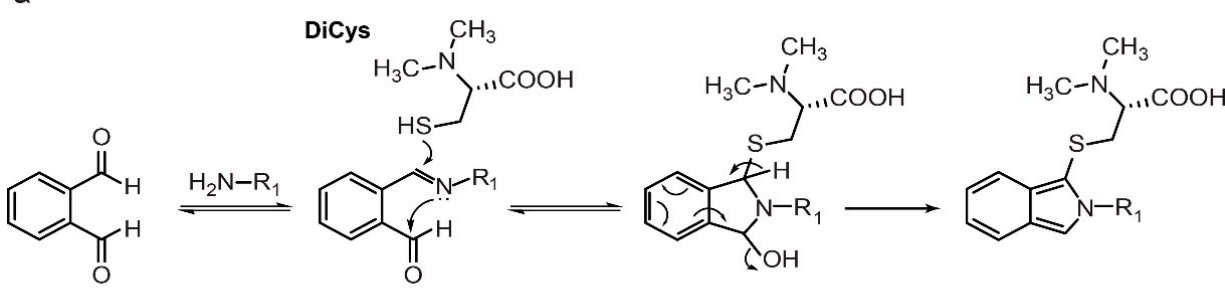

b<smiles>CCOC(=O)[C@H](CS)NC(=S)NC(C)(C)S</smiles>

Figure 1. (a) Derivatization reaction of amino acids with DiCys/OPA. (b) Structures of chiral thiols: NAC, NAP, IBLC, NBC, and BTCC.

\section{Results and Discussion}

\subsection{Stability and Fluorescence of DiCys Derivatives}

Some of the most abundant amine-containing metabolites in biological samples are amino acids. $\mathrm{L}$ and $\mathrm{D}$ amino acid pairs are also among the most important enantiomeric metabolites in terms of biological functions. The charged carboxylate group makes it somewhat challenging to resolve all 20 proteinogenic amino acids by RP-HPLC. Therefore, we chose amino acids as model metabolites to study DiCys/OPA derivatization. 
One of the reported disadvantages of OPA/thiol derivatization is the instability of the product $[24,25]$. Here, we evaluated the stability of OPA adducts with DiCys and five additional chiral thiols-NAC, NAP, IBLC, NBC, and BTCC. We monitored the fluorescence intensities of OPA/thiol-derivatized amino acids at $4{ }^{\circ} \mathrm{C}$ for $60 \mathrm{~min}$ (Figure S2 supplementary materials), and there was no visible sign of fluorophore breakdown, consistent with previous reports [37]. This should therefore be stable enough for routine LC-MS workflows.

We also quantified the fluorescence intensities of five L-amino acids derivatized with six chiral thiols (Figure 2a) after HPLC separation. Our results indicated that IBLC, NAC, and DiCys derivatives produced stronger fluorescence. In contrast, the NAP and NBC derivatives exhibited very low fluorescence intensities.

a

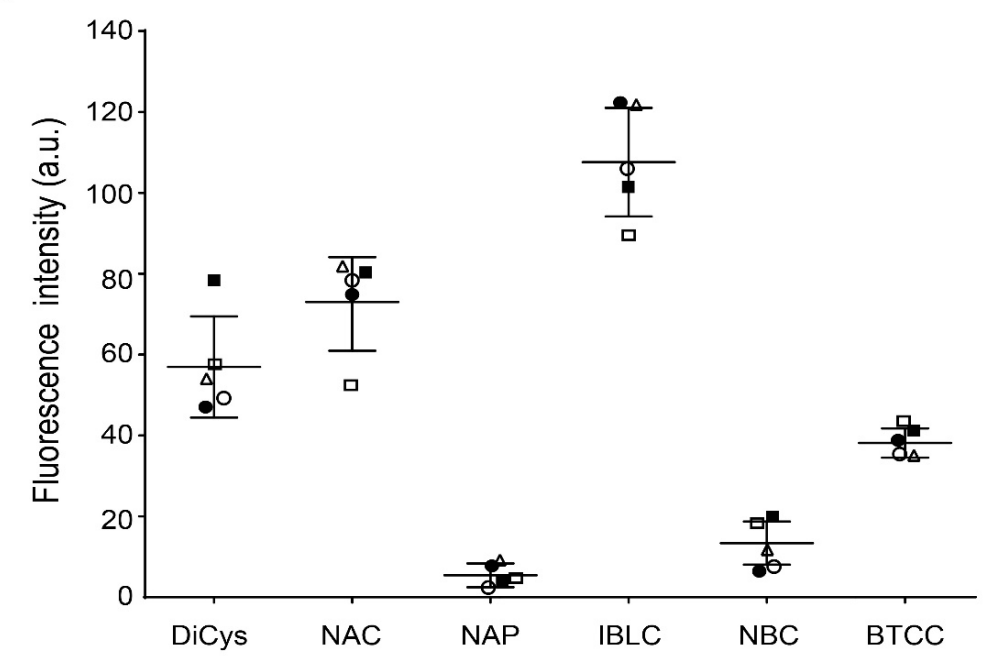

b

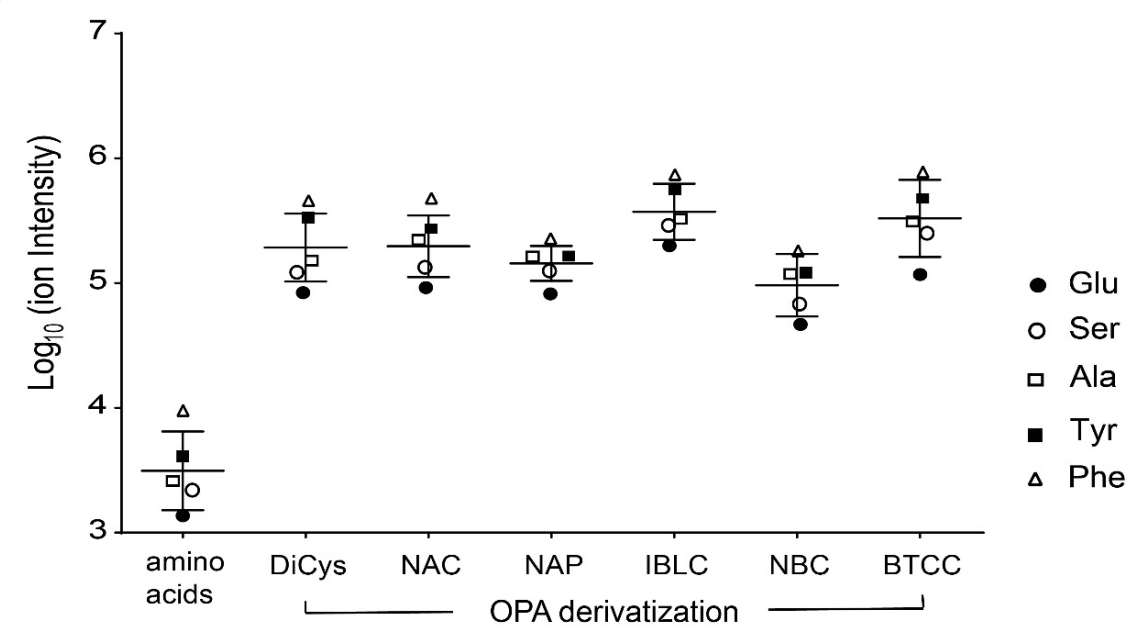

Figure 2. Fluorescence intensities (a) and ion intensities (b) of the OPA/thiol-derivatized L-amino acids (Glu, Ser, Ala, Tyr, and Phe) at equal concentrations. The center bar represents the mean, and the whiskers represent \pm 2 standard deviations.

\subsection{Separation of Enantiomers}

When Chernobrrovkin et al. compared NAC, NAP, IBLC, and NMC as chiral thiols for OPA derivatization [33], they found that NAC and NMC provided better chiral resolution than NAP and IBLC. However, the resolution factors may depend on the column; mobile phase composition; flow rate; and gradient $[38,39]$. We previously found that optimal elution condition for OPA adducts was around $\mathrm{pH} 8$ instead of the typical acidic condi- 
tions [40]. Therefore, we conducted RP-LC separation at $\mathrm{pH} 8$ to resolve five enantiomer pairs (Glu, Ser, Ala, Tyr, and Phe) (Figure 3). The best resolution was obtained with IBLC and DiCys, and the worst was with BTCC (Table S1 supplementary materials). Quantitative conversion to derivatized products for both enantiomers and the lack of racemization were confirmed by MS detection.

a

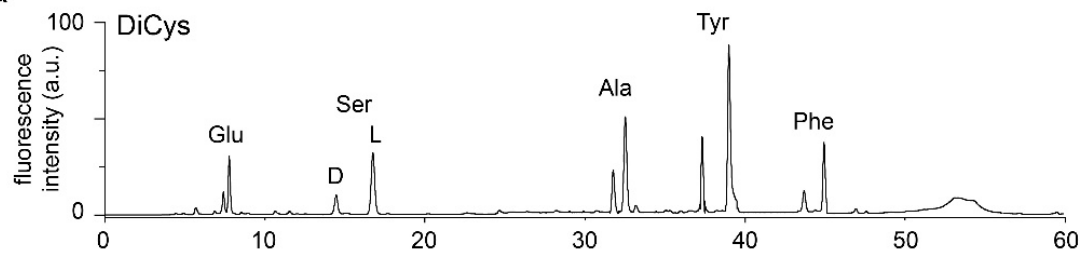

b

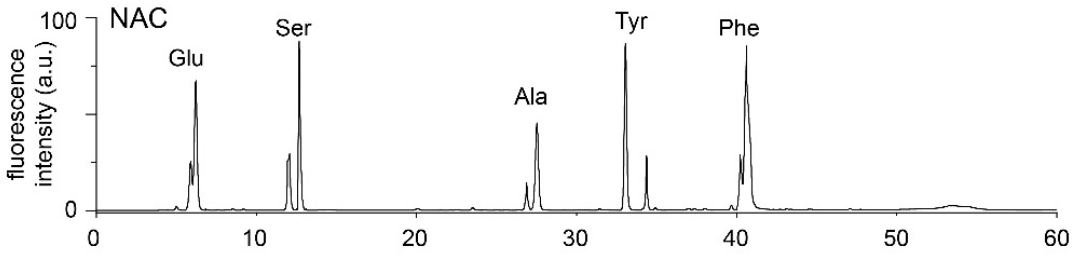

C

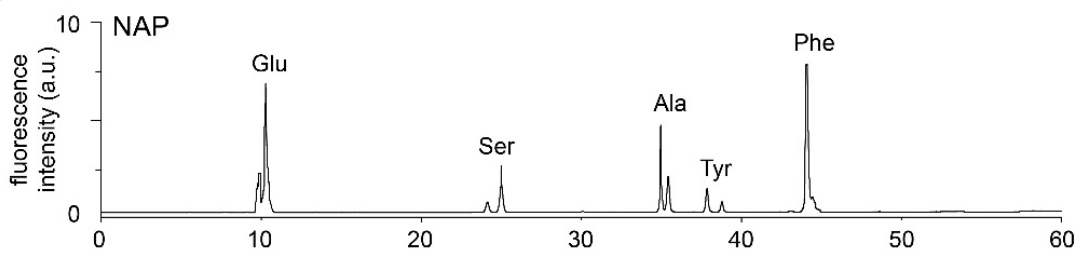

d

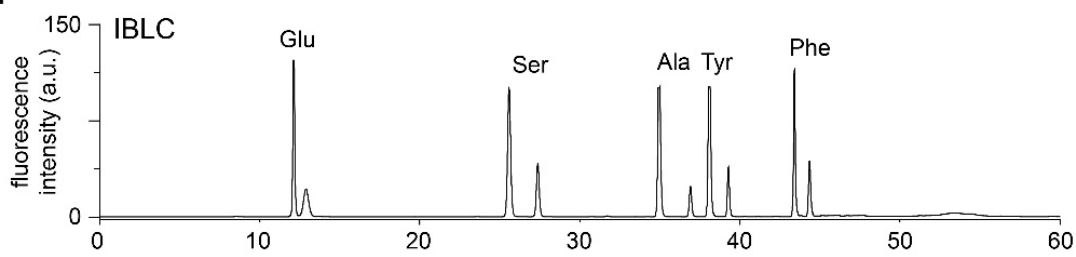

e

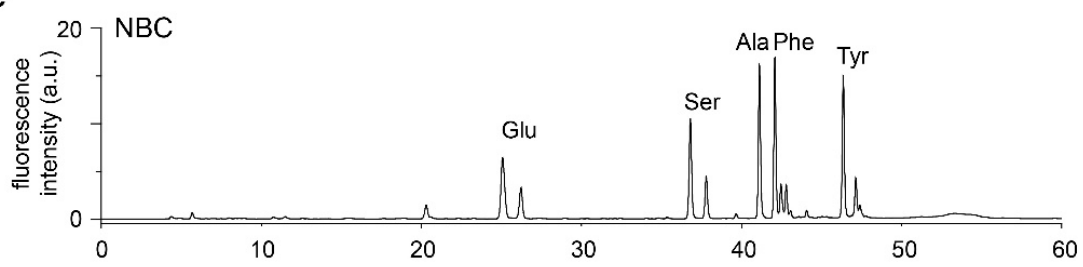

f

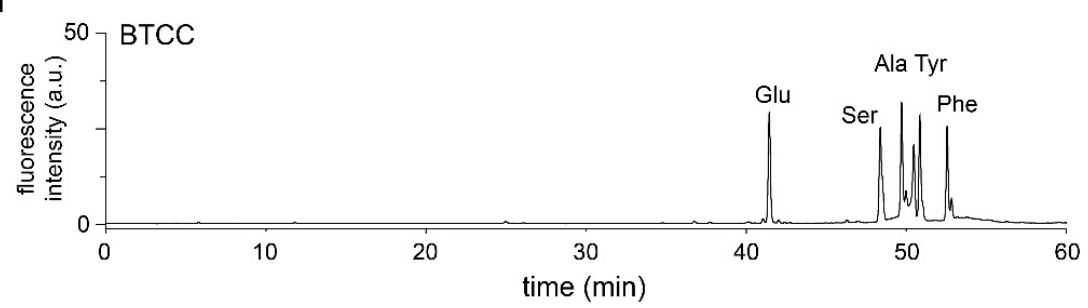

Figure 3. RP-HPLC analysis of amino acid enantiomers derivatized with OPA/thiol. The adducts of DiCys (a), NAC (b), NAP (c), IBLC (d), NBC (e), and BTCC (f) are detected by $340 \mathrm{~nm}$ excitation/450 $\mathrm{nm}$ emission. The ratio between $\mathrm{L}: \mathrm{D}$ amino acids is 3:1. 


\subsection{Ionization Efficiency and MS/MS Properties}

Amino acids exhibit low ionization efficiencies in ESI-MS experiments, and OPA derivatization may bring significant enhancements [40]. As shown in Figure 2b, all six thiol adducts have shown 25-100-fold higher ionization efficiencies over non-derivatized amino acids, making them generally useful for ESI-MS detection. In MS analyses, it is easy to identify derivatized amino acid enantiomers in the mass chromatogram based on doublepeak detection via selected ion monitoring. To fragment OPA adducts requires relatively high collision energies: around $20 \mathrm{~V}$ [40]. The fragmentation patterns of DiCys/OPA adducts with seven amino acids are shown in Figure S3 supplementary materials, with a neutral loss of the thiol group in all cases.

\subsection{Comparing DiCys/OPA against Marfey's Reagents}

For the enantiomeric separation of amino acids, Marfey's reagent has been used widely [41-44]. This has led to the development of several Marfey variants, including: 1fluoro-2-4-dinitrophenyl-5-L-alanine amide (FDAA); 1-fluoro-2-4-dinitrophenyl-5-L-Valina amide (FDVA); and the corresponding Phe, Ile, and Leu versions [44]. Here, we compared the most commonly used Marfey's variants, FDAA and FDVA, to the performance of DiCys/OPA. DiCys was the best of the three regarding chiral amino acid separation (Figure S4 supplementary materials). DiCys/OPA derivatives also have the advantage of being fluorogenic, while Marfey's derivatives are non-fluorescent. Therefore, we conclude that DiCys/OPA is highly suitable for resolving chiral analytes, better than popular methods such as NAC/OPA and Marfey's reagents.

\subsection{Enantiomer Identification in Rice Water with DiCys/OPA}

To test the usefulness of DiCys/OPA, we analyzed the aqueous extracts of edible rice, otherwise known as rice water. Rice water is the starchy water that remains after soaking or cooking rice, containing vitamins, amino acids, and minerals. It has been used traditionally in the treatment of skin and hair in Asian countries [45-47]. Little is known about the composition of amino acid enantiomers in rice water. Therefore, we separately applied DiCys/OPA and IBLC/OPA derivatization to rice water samples. Their RP-HPLC chromatograms are shown in Figure 4, and we observed almost twice as many visible fluorescent peaks with DiCys compared to IBLC. It shows that DiCys is suitable for separating a wide range of naturally occurring amine metabolites.

By MS and MS/MS detection, we could identify all twenty proteinogenic L-amino acids and seven D-amino acids (Ala, Arg, Lys, Phe, Ser, Tyr, and Val) in rice water samples using either DiCys or IBLC. Figure 5 shows the integrated ion intensities of individual amino acids. The retention time, precursor ion, and product ion information are listed in Tables S2 and S3 supplementary materials. The ratios between D/L amino acids are shown in Table 1. Interestingly, the highest D/L ratios were found for the two positively charged amino acids, Arg and Lys. Their physiological roles and gustatory effects remain undetermined.

\section{Materials and Methods}

\subsection{Reagents}

L and D amino acids (Glu, Ser, Ala, Tyr, Phe), L-Cys, OPA, ammonium bicarbonate, perchloric acid (ACS reagent, 70\%), formaldehyde (37\% $w / w)$, dichloromethane, ninhydrin, fluorescamine, Ellman's reagent (DTNB), NAC, NAP, IBLC, NBC, and BTCC were purchased from Sigma-Aldrich (St. Louis, MO, USA). Methanol and acetonitrile (ACN) were purchased from Baker (Radnor, PA, USA). Boric acid and sodium tetraborate were purchased from Acros (Geel, Belgium). Sodium cyanoborohydride was purchased from Fluka (Buchs, Switzerland). FDAA and FDVA were purchased from Thermo Fisher (Waltham, MA, USA). 
a

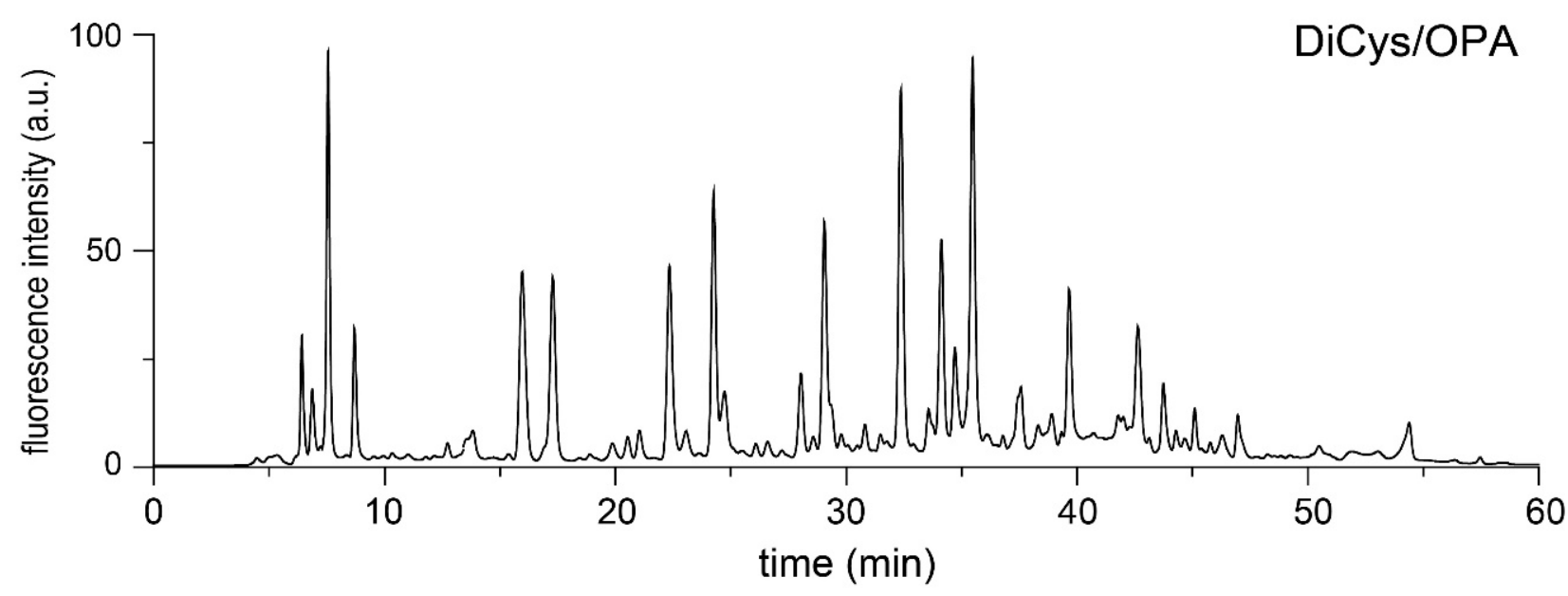

b

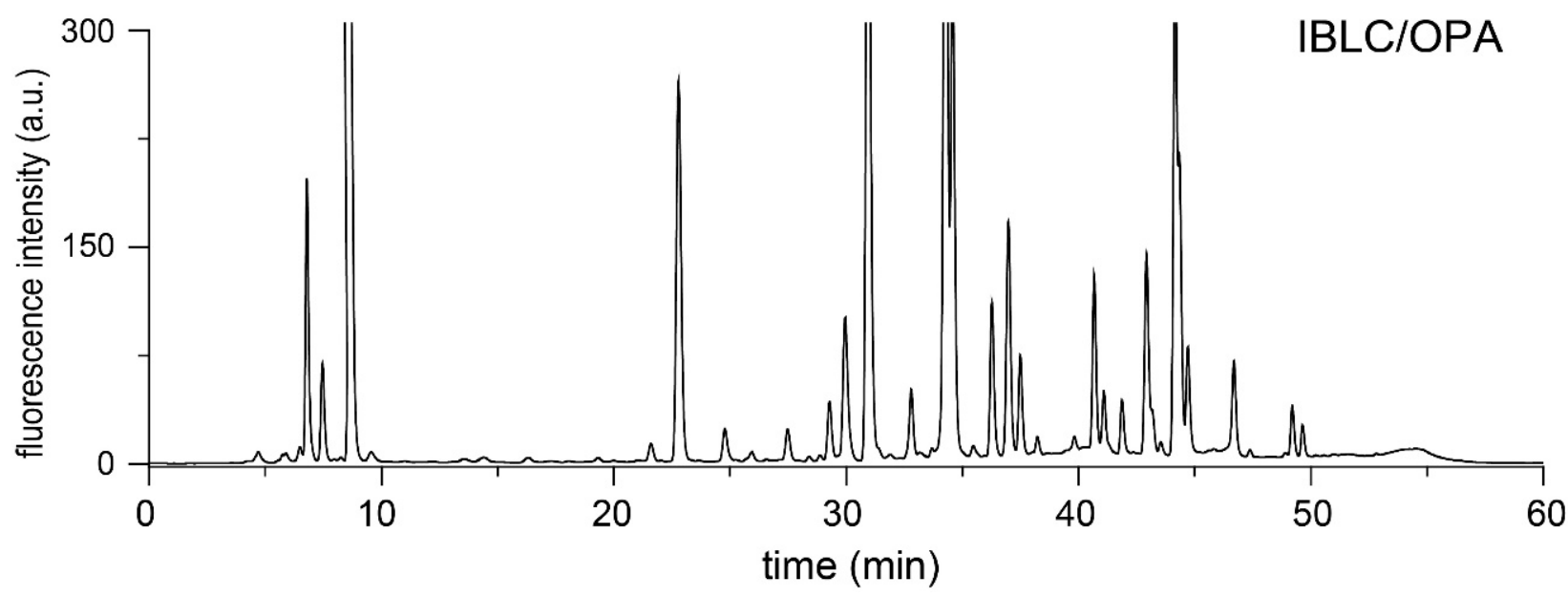

Figure 4. RP-HPLC analysis of free amines in rice water derivatized by DiCys/OPA (a) and IBLC/OPA (b), detected by $340 \mathrm{~nm}$ excitation/450 $\mathrm{nm}$ emission.

\subsection{Synthesis of N,N-Dimethyl-L-Cysteine}

A total of $100 \mathrm{mg}$ of L-cysteine was dissolved in $10 \mathrm{~mL}$ dilute $\mathrm{HCl}(\mathrm{pH} \mathrm{2.5)}$ and mixed with $8.25 \mathrm{mmol}$ of sodium cyanoborohydride $\left(\mathrm{NaBH}_{3} \mathrm{CN}\right)$ for $10 \mathrm{~min}$ at $4{ }^{\circ} \mathrm{C}$. Then, $8.25 \mathrm{mmol}$ of formaldehyde $(37 \% \mathrm{w} / \mathrm{w})$ was added, stirred for $30 \mathrm{~min}$, and the reaction was monitored by ninhydrin staining on thin-layer chromatography plates. The DiCys product was purified via silica-gel column chromatography using $\mathrm{MeOH} / \mathrm{CH}_{2} \mathrm{Cl}_{2}$. DiCys fraction was acidified to $\mathrm{pH} 2.5$ by adding $0.1 \mathrm{~N} \mathrm{HCl}$ and evaporated to dryness at $60{ }^{\circ} \mathrm{C}$. DiCys powder was dissolved in deionized water and quantified using the Ellman assay. The reaction yield was $87 \%$. HRMS (ESI/Q-TOF) $m / z: \mathrm{M}=\mathrm{C}_{5} \mathrm{H}_{11} \mathrm{NO}_{2} \mathrm{~S}$, calculated for $[\mathrm{M}+\mathrm{H}]^{+}=150.0583$, found 150.0589 .

\subsection{Rice Water Preparation}

Sushi rice samples were purchased from a local grocery store in Taiwan. In total, $50 \mathrm{~g}$ of the dried rice was placed in $50 \mathrm{~mL}$ of deionized water. After shaking for $30 \mathrm{~min}$, the solution was passed through filter paper. The rice water was lyophilized and dissolved in $250 \mu \mathrm{L}$ of $0.01 \%$ perchloric acid and filtered twice through $0.22 \mu \mathrm{m}$ nylon filters. Finally, we quantified total amines using a fluorescamine assay [48]. 


\section{Integrated peak area}

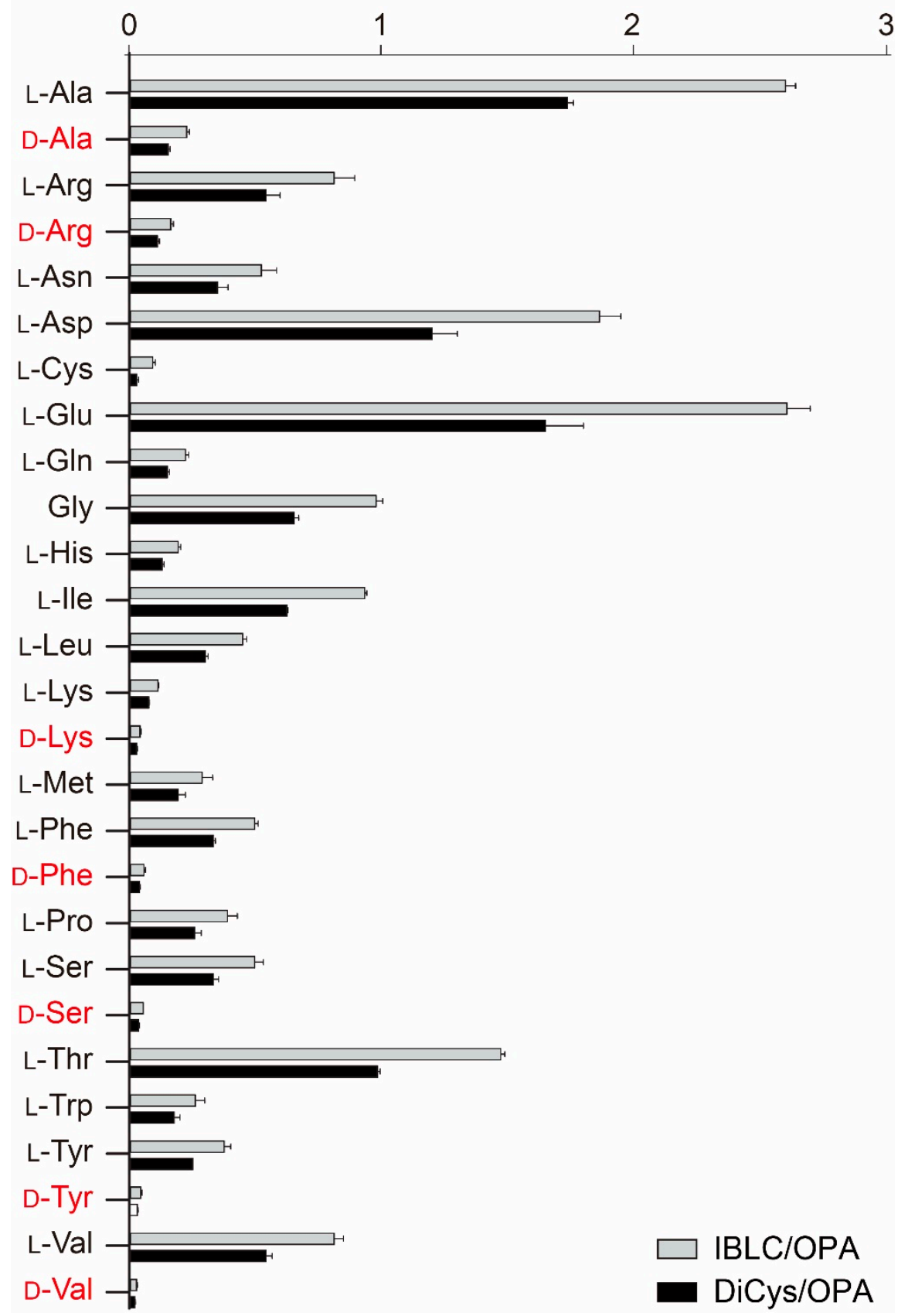

Figure 5. The amino acid contents of rice water measured by IBLC/OPA and DiCys/OPA derivatization. Bars indicate the integrated peak area of ion intensities from RP-LC-MS analyses. Error bars correspond to the standard error from three independent replicate experiments.

Table 1. The ratios of D-amino acid to L-amino acid in rice water.

\begin{tabular}{cc}
\hline Amino Acids & D/L Ratio \\
\hline Ala & 0.09 \\
Arg & 0.31 \\
Lys & 0.30 \\
Phe & 0.09 \\
Ser & 0.10 \\
Tyr & 0.12 \\
Val & 0.03 \\
\hline
\end{tabular}




\subsection{Derivatization Reactions}

The following reagents were prepared freshly before use: L, D-glutamic acid; L, Dserine; L, D-alanine; L, D-arginine; D-valine; L, D-tyrosine; L, D-phenylalanine; and L, D-lysine. These reagents were used as amino acid standards and dissolved in $0.01 \%$ perchloric acid. The thiols (DiCys, NAC, NAP, IBLC, NBC, and BTCC) were dissolved in methanol to $150 \mathrm{mM}$. The OPA solution $(50 \mathrm{mM})$ was prepared by dissolving $1.5 \mathrm{mg}$ OPA in a mixture of $20 \mu \mathrm{L} \mathrm{MeOH}$ and $180 \mu \mathrm{L}$ of $1 \mathrm{M}$ borate buffer ( $\mathrm{pH} 10.7$ ); then, $5.03 \mathrm{mg}$ of FDAA was dissolved in $500 \mu \mathrm{L} \mathrm{ACN}(37 \mathrm{mM}$ ), and $5.55 \mathrm{mg}$ of FDVA in $500 \mu \mathrm{L} \mathrm{ACN}$ (37 mM).

After this, $20 \mu \mathrm{L}$ of $50 \mathrm{mM}$ OPA, $20 \mu \mathrm{L}$ of $1 \mathrm{M}$ borate buffer (pH 10.7), and $20 \mu \mathrm{L}$ of $150 \mathrm{mM}$ thiol were combined. We then added either $20 \mu \mathrm{L}$ of $2.5 \mathrm{mM}$ amino acid solution or rice water sample, and the mixture was vortexed and incubated at $4{ }^{\circ} \mathrm{C}$ for 2 min under dark conditions. The solution was diluted to a final volume of $200 \mu \mathrm{L}$ with $50 \% \mathrm{ACN}$, and $20 \mu \mathrm{L}$ of the mixture was injected into the HPLC.

A total of $20 \mu \mathrm{L}$ of $37 \mathrm{mM}$ Marfey's reagent (FDAA or FDVA) was mixed with $20 \mu \mathrm{L}$ of $2.5 \mathrm{mM}$ amino acid solution, $8 \mu \mathrm{L}$ of $1 \mathrm{M} \mathrm{NaHCO}_{3}(\mathrm{pH} 8.0$ ), and $31.5 \mu \mathrm{L}$ of acetone. The mixture was incubated at $40^{\circ} \mathrm{C}$ for $1 \mathrm{~h}$, quenched by adding $6 \mu \mathrm{L}$ of $2 \mathrm{M} \mathrm{HCl}$, before $20 \mu \mathrm{L}$ of the mixture was injected into the HPLC.

\subsection{LC-MS Analysis}

The Agilent 1260 HPLC system (Santa Clara, CA, USA) was equipped with an autosampler, a quaternary pump, a column oven, a UV-Vis absorbance detector, and a fluorescence detector. The Hydrosphere C18 column $(250 \times 4.6 \mathrm{~mm}, 5 \mu \mathrm{m}$ bead diameter) used for separation was acquired from YMC (Kyoto, Japan). The aqueous mobile phase (A) consisted of $2 \mathrm{mM}$ ammonium bicarbonate ( $\mathrm{pH} 8.0$ ), whilst mobile phase $\mathrm{B}$ contained $7 \% \mathrm{MeOH}$ in $\mathrm{ACN}$. Elution was performed at a flow rate of $1 \mathrm{~mL} / \mathrm{min}$ at $40{ }^{\circ} \mathrm{C}$ using the following gradient program: 0-5 min, 10\%; 5-10 min, 10-12\%; 10-20 min, $12-22 \%$; 20-30 min, 22-38\%; 30-40 min, 38-60\%; 40-47 min, 60-83\%; 47-50 min, 83-100\%; 50-54 min, $100 \%$; 54-57 $\mathrm{min}, 100-10 \%$; 57-60 min, 10\%. The HPLC was connected to Bruker micrOTOF-QII (Bremen, Germany) operated in positive mode. Full MS spectra were recorded from $(\mathrm{m} / z)$ 100 to 600 . ESI source parameters were nebulizer gas (nitrogen) at 0.3 bar, drying gas (nitrogen) at $4 \mathrm{~L} / \mathrm{min}$, and $180{ }^{\circ} \mathrm{C}$.

\section{Conclusions}

We systematically evaluated the suitability of six chiral thiols (DiCys, NAC, NAP, IBLC, NBC, and BTCC) for OPA-assisted separation of amino acid enantiomers. The best separation efficiencies in RP-HPLC were found with DiCys and IBLC. For fluorescence detection, IBLC, NAC, and DiCys gave stronger signals while NAP only gave very weak signals. All six reagents enhanced ionization efficiencies by $25-100$ fold, useful for MS detection. Previously, IBLC has been a popular reagent for resolving chiral amino acids [30,49], and our data supported its usefulness. More importantly, our study was the first to introduce DiCys/OPA for enantiomeric separation, and its performance was comparable to IBLC in our tests. DiCys also outperformed Marfey's reagents FDAA and FDVA, which were specially developed for chiral separation purposes. We conclude that DiCys is a highly versatile reagent for resolving enantiomeric amines in chiral metabolomics experiments.

The greatest advantage of DiCys is its potential for multiplex heavy-isotope labeling. Using well-established chemistries [35], heavy isotope versions from +1 Da to +9 Da may be easily synthesized in one step using commercially available reagents. This may provide 10-plex labeling at an affordable cost for high-throughput metabolomics experiments. Combined with fluorogenic detection and excellent chiral separation, DiCys is one of the most versatile amine derivatization reagents currently available.

In real-world metabolomics profiling of rice water, DiCys provided better separation of amine metabolites than IBLC. Both allowed us to detect twenty proteinogenic L-amino acids and identify seven D-amino acids-Ala, Arg, Lys, Phe, Ser, Tyr, and Val. These D-amino 
acids are primarily associated with sweetness for humans [50,51], suggesting that D-amino acids may be important for the gustatory taste. Moreover, D-amino acids synthesized by gut microbiomes may affect our immune systems [52,53]. How D-amino acids in rice diet may affect our gut microbiome-immune axis will warrant further investigation.

Supplementary Materials: The following are available online: Figures S1-S4 and Tables S1-S3.

Author Contributions: A.L. conducted the experiments. A.L. and H.-C.T. designed the experiments and wrote the manuscript. All authors have read and agreed to the published version of the manuscript.

Funding: This research received no external funding.

Institutional Review Board Statement: Not applicable.

Informed Consent Statement: Not applicable.

Data Availability Statement: Not applicable.

Acknowledgments: We thank Yun-Shiuan Leung and the Mass Spectrometry Core Facility at Department of Chemistry, National Taiwan University for LC-MS support.

Conflicts of Interest: The authors declare no conflict of interest.

Sample Availability: Not applicable.

\section{References}

1. Weckwerth, W. Metabolomics: An integral technique in systems biology. Bioanalysis 2010, 2, 829-836. [CrossRef] [PubMed]

2. Sevin, D.C.; Kuehne, A.; Zamboni, N.; Sauer, U. Biological insights through nontargeted metabolomics. Curr. Opin. Biotechnol. 2015, 34, 1-8. [CrossRef] [PubMed]

3. Beger, R.D.; Dunn, W.; Schmidt, M.A.; Gross, S.S.; Kirwan, J.A.; Cascante, M.; Brennan, L.; Wishart, D.S.; Oresic, M.; Hankemeier, T.; et al. Metabolomics enables precision medicine: "A White Paper, Community Perspective". Metabolomics 2016, 12, 149. [CrossRef] [PubMed]

4. Johnson, C.H.; Ivanisevic, J.; Siuzdak, G. Metabolomics: Beyond biomarkers and towards mechanisms. Nat. Rev. Mol. Cell Biol. 2016, 17, 451-459. [CrossRef]

5. Fuhrer, T.; Zamboni, N. High-throughput discovery metabolomics. Curr. Opin. Biotechnol. 2015, 31, 73-78. [CrossRef]

6. Zampieri, M.; Sekar, K.; Zamboni, N.; Sauer, U. Frontiers of high-throughput metabolomics. Curr. Opin. Chem. Biol. 2017, 36, 15-23. [CrossRef]

7. Huan, T.; Wu, Y.; Tang, C.; Lin, G.; Li, L. DnsID in MyCompoundID for rapid identification of dansylated amine- and phenolcontaining metabolites in LC-MS-based metabolomics. Anal. Chem. 2015, 87, 9838-9845. [CrossRef]

8. Zhou, R.; Guo, K.; Li, L. 5-Diethylamino-naphthalene-1-sulfonyl chloride (DensCl): A novel triplex isotope labeling reagent for quantitative metabolome analysis by liquid chromatography mass spectrometry. Anal. Chem. 2013, 85, 11532-11539. [CrossRef]

9. SG, B.G.; Gowda, D.; Liang, C.; Li, Y.; Kawakami, K.; Fukiya, S.; Yokota, A.; Chiba, H.; Hui, S.P. Chemical Labeling Assisted Detection and Identification of Short Chain Fatty Acid Esters of Hydroxy Fatty Acid in Rat Colon and Cecum Contents. Metabolites 2020, 10, 398 .

10. Toyo'oka, T. Derivatization-based High-throughput Bioanalysis by LC-MS. Anal. Sci. 2017, 33, 555-564.

11. Koga, R.; Yoshida, H.; Nohta, H.; Hamase, K. Multi-dimensional hplc analysis of metabolic related chiral amino acids-method development and biological/clinical applications. Chromatography 2019, 40,1-8. [CrossRef]

12. Pandey, R.; Collins, M.; Lu, X.; Sweeney, S.R.; Chiou, J.; Lodi, A.; Tiziani, S. Novel Strategy for Untargeted Chiral Metabolomics using Liquid Chromatography-High Resolution Tandem Mass Spectrometry. Anal. Chem. 2021, 93, 5805-5814. [CrossRef]

13. Takayama, T.; Mochizuki, T.; Todoroki, K.; Min, J.Z.; Mizuno, H.; Inoue, K.; Akatsu, H.; Noge, I.; Toyo'oka, T. A novel approach for LC-MS/MS-based chiral metabolomics fingerprinting and chiral metabolomics extraction using a pair of enantiomers of chiral derivatization reagents. Anal. Chim. Acta 2015, 898, 73-84. [CrossRef]

14. Mochizuki, T.; Todoroki, K.; Inoue, K.; Min, J.Z.; Toyo'oka, T. Isotopic variants of light and heavy L-pyroglutamic acid succinimidyl esters as the derivatization reagents for DL-amino acid chiral metabolomics identification by liquid chromatography and electrospray ionization mass spectrometry. Anal. Chim. Acta 2014, 811, 51-59. [CrossRef]

15. Takayama, T.; Kuwabara, T.; Maeda, T.; Noge, I.; Kitagawa, Y.; Inoue, K.; Todoroki, K.; Min, J.Z.; Toyo'oka, T. Profiling of chiral and achiral carboxylic acid metabolomics: Synthesis and evaluation of triazine-type chiral derivatization reagents for carboxylic acids by LC-ESI-MS/MS and the application to saliva of healthy volunteers and diabetic patients. Anal. Bioanal. Chem. 2015, 407, 1003-1014. [CrossRef] [PubMed]

16. Hamase, K.; Morikawa, A.; Etoh, S.; Tojo, Y.; Miyoshi, Y.; Zaitsu, K. Analysis of small amounts of D-amino acids and the study of their physiological functions in mammals. Anal. Sci. 2009, 25, 961-968. [CrossRef] [PubMed] 
17. Miyoshi, Y.; Koga, R.; Oyama, T.; Han, H.; Ueno, K.; Masuyama, K.; Itoh, Y.; Hamase, K. HPLC analysis of naturally occurring free d-amino acids in mammals. J. Pharm. Biomed. Anal. 2012, 69, 42-49. [CrossRef]

18. Bastings, J.J.; van Eijk, H.M.; Olde Damink, S.W.; Rensen, S.S. d-amino Acids in Health and Disease: A Focus on Cancer. Nutrients 2019, 11, 2205. [CrossRef] [PubMed]

19. Kumar, A.P.; Jin, D.; Lee, Y.-I. Recent development on spectroscopic methods for chiral analysis of enantiomeric compounds. Appl. Spectrosc. Rev. 2009, 44, 267-316. [CrossRef]

20. Fanali, C.; D'Orazio, G.; Gentili, A.; Fanali, S. Analysis of enantiomers in products of food interest. Molecules 2019, $24,1119$. [CrossRef]

21. Hui, M.; Cheung, S.-W.; Chin, M.-L.; Chu, K.-C.; Chan, R.C.-Y.; Cheng, A.F.-B. Development and application of a rapid diagnostic method for invasive Candidiasis by the detection of D-/L-arabinitol using gas chromatography/mass spectrometry. Diagn. Microbiol. Infect. Dis. 2004, 49, 117-123. [CrossRef] [PubMed]

22. Nguyen, L.A.; He, H.; Pham-Huy, C. Chiral drugs: An overview. Int. J. Biomed. Sci. 2006, 2, 85-100. [PubMed]

23. Takayama, T.; Mizuno, H.; Toyo'oka, T.; Akatsu, H.; Inoue, K.; Todoroki, K. Isotope Corrected Chiral and Achiral Nontargeted Metabolomics: An Approach for High Accuracy and Precision Metabolomics Based on Derivatization and Its Application to Cerebrospinal Fluid of Patients with Alzheimer's Disease. Anal. Chem. 2019, 91, 4396-4404. [CrossRef]

24. Guranda, D.T.; Kudryavtsev, P.A.; Khimiuk, A.Y.; Švedas, V.K. Efficient enantiomeric analysis of primary amines and amino alcohols by high-performance liquid chromatography with precolumn derivatization using novel chiral $\mathrm{SH}-$ reagent $N-(R)-$ mandelyl-(S)-cysteine. J. Chromatogr. A 2005, 1095, 89-93. [CrossRef] [PubMed]

25. Molnár-Perl, I. HPLC of amino acids as o-phthalaldehyde derivatives. J. Chromatogr. Libr. 2005, 70, $163-198$.

26. Molnár-Perl, I. Advancement in the derivatizations of the amino groups with the o-phthaldehyde-thiol and with the 9fluorenylmethyloxycarbonyl chloride reagents. J. Chromatogr. B 2011, 879, 1241-1269. [CrossRef]

27. Gowda, S.G.B.; Nakahashi, A.; Yamane, K.; Nakahashi, S.; Murai, Y.; Siddegowda, A.K.C.; Hammam, M.A.S.; Monde, K. Facile Chemoselective Strategy toward Capturing Sphingoid Bases by a Unique Glutaraldehyde-Functionalized Resin. ACS Omega 2018, 3, 753-759. [CrossRef]

28. Yokoyama, T.; Tokuda, M.; Amano, M.; Mikami, K. Simultaneous determination of primary and secondary D- and L-amino acids by reversed-phase high-performance liquid chromatography using pre-column derivatization with two-step labelling method. Biosci. Biotechnol. Biochem. 2017, 81, 1681-1686. [CrossRef]

29. Brückner, H.; Wittner, R.; Godel, H. Amino acid analysis by derivatization with $o$-phthaldialdehyde and chiral thiols. In Amino Acids; Lubec, G., Rosenthal, G.A., Eds.; Springer: Dordrecht, The Netherlands, 1990; pp. 143-151.

30. Fitznar, H.P.; Lobbes, J.M.; Kattner, G. Determination of enantiomeric amino acids with high-performance liquid chromatography and pre-column derivatisation with $o$-phthaldialdehyde and $\mathrm{N}$-isobutyrylcysteine in seawater and fossil samples (mollusks). J. Chromatogr. A 1999, 832, 123-132. [CrossRef]

31. Brückner, H.; Zivny, S. High-performance liquid chromatographic resolution of $(R, S)$ - $\alpha$-alkyl- $\alpha$-amino acids as diastereomeric derivatives. Amino Acids 1993, 4, 157-167. [CrossRef]

32. Nimura, N.; Fujiwara, T.; Watanabe, A.; Sekine, M.; Furuchi, T.; Yohda, M.; Yamagishi, A.; Oshima, T.; Homma, H. A novel chiral thiol reagent for automated precolumn derivatization and high-performance liquid chromatographic enantioseparation of amino acids and its application to the aspartate racemase assay. Anal. Biochem. 2003, 315, 262-269. [CrossRef]

33. Chernobrovkin, M.; Shapovalova, E.; Guranda, D.; Kudryavtsev, P.; Švedas, V.; Shpigun, O. Chiral high-performance liquid chromatography analysis of $\alpha$-amino acid mixtures using a novel SH reagent- $N$ - $R$-mandelyl-L-cysteine and traditional enantiomeric thiols for precolumn derivatization. J. Chromatogr. A 2007, 1175, 89-95. [CrossRef]

34. Lóki, K.; Varga-Visi, É.; Albert, C.; Csapó, J. Separation and determination of the tryptophan enantiomers. Acta Univ. Sapientiae 2008, 1, 61-71.

35. Hsu, J.L.; Chen, S.H. Stable isotope dimethyl labelling for quantitative proteomics and beyond. Philos. Trans. A Math. Phys. Eng. Sci. 2016, 374, 20150364. [CrossRef] [PubMed]

36. Kovanich, D.; Cappadona, S.; Raijmakers, R.; Mohammed, S.; Scholten, A.; Heck, A.J. Applications of stable isotope dimethyl labeling in quantitative proteomics. Anal. Bioanal. Chem. 2012, 404, 991-1009. [CrossRef] [PubMed]

37. Chen, R.F.; Scott, C.; Trepman, E. Fluorescence properties of $o$-phthaldialdehyde derivatives of amino acids. Biochim. Biophys. Acta Protein Struct. 1979, 576, 440-455. [CrossRef]

38. Gurram, I.; Kavitha, M.; Nagabhushnam, M.; Bonthagara, B.; Reddy, D.N. Overview of validation, basic concepts and analytical method process validation. Indian J. Pharm. Sci. 2017, 4, 1665-1680.

39. Sabir, A.; Moloy, M.; Bhasin, P. HPLC Method Development and Validation: A Review. Int. Res. J. Pharm. 2015, 4, 39-46. [CrossRef]

40. Lkhagva, A.; Shen, C.-C.; Leung, Y.-S.; Tai, H.-C. Comparative study of five different amine-derivatization methods for metabolite analyses by liquid chromatography-tandem mass spectrometry. J. Chromatogr. A 2020, 1610, 460536. [CrossRef]

41. Ayon, N.J.; Sharma, A.D.; Gutheil, W.G. LC-MS/MS-based separation and quantification of Marfey's reagent derivatized proteinogenic amino acid DL-stereoisomers. J. Am. Soc. Mass Spectrom. 2018, 30, 448-458. [CrossRef]

42. Bhushan, R.; Brückner, H. Marfey's reagent for chiral amino acid analysis: A review. Amino Acids 2004, 27, 231-247. [CrossRef] [PubMed] 
43. Bruckner, H.; Gah, C. High-performance liquid chromatographic separation of DL-amino acids derivatized with chiral variants of Sanger's reagent. J. Chromatogr. A 1991, 555, 81-95. [CrossRef]

44. Marfey, P. Determination of D-amino acids. II. Use of a bifunctional reagent, 1, 5-difluoro-2, 4-dinitrobenzene. Carlsberg Res. Commun. 1984, 49, 591-596. [CrossRef]

45. Inamasu, S.; Ikuyama, R.; Fujisaki, Y.; Sugimoto, K.I. The effect of rinse water obtained from the washing of rice (YU-SU-RU) as a hair treatment. J. Soc. Cosmet. Chemists Japan 2010, 44, 29-32. [CrossRef]

46. Kalman, D.S. Amino acid composition of an organic brown rice protein concentrate and isolate compared to soy and whey concentrates and isolates. Foods 2014, 3, 394-402. [CrossRef]

47. Wong, H. Rice water in treatment of infantile gastroenteritis. Lancet 1981, 2, 102-103. [CrossRef]

48. Chung, L. A fluorescamine assay for membrane protein and peptide samples with non-amino-containing lipids. Anal. Biochem. 1997, 248, 195-201. [CrossRef]

49. Müller, C.; Fonseca, J.R.; Rock, T.M.; Krauss-Etschmann, S.; Schmitt-Kopplin, P. Enantioseparation and selective detection of D-amino acids by ultra-high-performance liquid chromatography/mass spectrometry in analysis of complex biological samples. J. Chromatogr. A 2014, 1324, 109-114. [CrossRef]

50. Kawai, M.; Sekine-Hayakawa, Y.; Okiyama, A.; Ninomiya, Y. Gustatory sensation of L-and D-amino acids in humans. Amino Acids 2012, 43, 2349-2358. [CrossRef]

51. Delompré, T.; Guichard, E.; Briand, L.; Salles, C. Taste Perception of Nutrients Found in Nutritional Supplements: A Review. Nutrients 2019, 11, 2050. [CrossRef]

52. Sasabe, J.; Miyoshi, Y.; Rakoff-Nahoum, S.; Zhang, T.; Mita, M.; Davis, B.M.; Hamase, K.; Waldor, M.K. Interplay between microbial D-amino acids and host d-amino acid oxidase modifies murine mucosal defence and gut microbiota. Nat. Microbiol. 2016, 1, 16125. [CrossRef] [PubMed]

53. Sasabe, J.; Suzuki, M. Emerging Role of D-Amino Acid Metabolism in the Innate Defense. Front. Microbiol. 2018, 9, 933. [CrossRef] [PubMed] 